\title{
BMJ Global Health How prevention of violence in childhood builds healthier economies and smarter children in the Asia and Pacific region
}

\author{
Deborah Fry, ${ }^{1}$ Stephen Blight ${ }^{2}$
}

To cite: Fry D, Blight S. How prevention of violence in childhood builds healthier economies and smarter children in the Asia and Pacific region. BMJ Global Health 2016;1 (Supp 2):e000188. doi:10.1136/bmjgh-2016000188

Received 15 September 2016 Accepted 14 October 2016

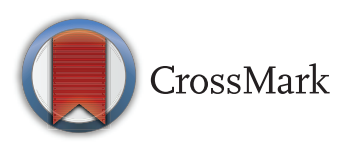

${ }^{1}$ Moray House School of Education, University of Edinburgh, Edinburgh, UK ${ }^{2}$ UNICEF East Asia and Pacific Regional Office, Bangkok, Thailand

Correspondence to Stephen Blight; sblight@unicef.org

\section{ABSTRACT}

Investments in preventing violence against children in the Asia and Pacific region will bring important social and economic returns that contribute to building the region's 'cognitive capital'. An analysis of burden of violence research in the region is presented to identify the impacts of violence and to demonstrate these returns. Violence is an everyday experience in the lives of many children in the Asia-Pacific, and the toxic stress associated with such routine forms of violence may permanently impact the architecture and chemistry of the developing brain. This can undermine learning and affect behavioural, social and emotional functioning as children grow into adulthood. Given the hundreds of millions of children affected by violence in the region each year, its cumulative impact translates into the annual loss of hundreds of billions of dollars -or about $2 \%$ of gross domestic product of the Asia and Pacific region. Violence prevention can affect positively on health and productivity, reduce expenditure on crisis response, improve children's developmental and educational outcomes, and prevent crime. The sustainable development goals and the emerging global consensus on effective prevention strategies constitute a powerful new agenda to end violence against children, and there are critical steps that governments can take to accelerate action.

\section{INTRODUCTION}

Children's right to protection from all forms of violence is established in international law. ${ }^{2}$ There should be no need to justify government action to prevent violence based on public health or economic arguments.

However, despite progress made in the 10 years following the Secretary-General's landmark report on violence against children, ${ }^{3}$ physical, emotional and sexual abuse and neglect remain remarkably common experiences in the lives of children in the Asia and Pacific region. ${ }^{4}$ Recent data show that the region has one of the highest pastyear prevalent rates of violence against children globally. ${ }^{5}$ While public attention is

\section{Key questions}

What is already known about this topic?

- Violence against children is prevalent and affects the health and well-being of children, adolescents and adults in every society where it has been measured.

What are the new findings?

- Estimates of lifetime prevalence of physical, sexual and emotional violence against children, neglect and witnessing domestic violence for boys and girls in the Asia and Pacific region.

- The magnitude of associations of experiencing violence in childhood with various outcomes to estimate the impact of violence against children and, for the first time, to provide an investment case for prevention of violence against children in the Asia-Pacific region.

\section{Recommendations for policy}

- For policymakers, this study helps situate child protection as a critical element within national agendas for the development of human capital. It highlights the significant public health impacts that are possible through government intervention to prevent and reduce frequently occurring forms of violence. It assists policymakers in identifying evidence-based strategies to end violence and sets out key priorities for action.

- Toxic stress associated with all forms of violence can permanently affect the architecture and chemistry of the developing brain undermining learning and behavioural, social and emotional functioning as children grow into adulthood. Early intervention is key to prevent these negative outcomes.

often focused on extreme or sensationalised forms or violence, the fact that children endure violence on a routine basis in everyday settings-within their families, at home and in schools-is frequently overlooked, socially accepted or even condoned in legislation. ${ }^{7}$ Yet a growing body of scientific 
research has established that experience of violence in childhood may have long-term consequences on the individual and society. ${ }^{8}$

This evidence is buttressed by neuroscientific findings that show how toxic stress associated with violence can disrupt the process of brain development and even cause changes in brain architecture and chemical activity. ${ }^{9}{ }^{10}$ Recent studies from the Asia and Pacific region have found that all forms of violence against children, including emotional, ${ }^{11}$ sexual $^{12-14}$ and physical ${ }^{15}{ }^{16}$ violence, may potentially result in visible harm to children's brains.

Recognising that none of the sustainable development goals (SDGs) for children can be met if children live in fear and experience the effects of violence, the SDGs include 5 goals and 11 targets addressing violence, abuse and exploitation. Together with a newly established consensus of evidence-based strategies, ${ }^{17}$ a powerful new agenda has emerged to end violence against children.

This paper presents an analysis of the burden of violence data to identify the impacts on health outcomes and productivity, education and crime. By analysing the literature and assembling summative estimates of lifetime prevalence, the magnitude of associations with various outcomes was calculated, and the impact of violence against children was estimated. The study advances the investment case for prevention of violence against children in the Asia and Pacific region.

\section{Prevalence of violence against children in the Asia-Pacific region}

A systematic review was conducted of prevalence and outcome studies from 33 countries in the Asia-Pacific region published between 2000 and $2010 .{ }^{4}$ On the basis of these data, the statistical associations between the various forms of violence and negative outcomes were calculated, including meta-analyses of prevalence and outcomes studies and the relationship between the two in the form of population attributable fractions (PAFs) ${ }^{18}$ The calculations for this paper are based on 47 studies from the data set that included prevalence and outcomes data and these were controlled for methodological variation and are sample-size-weighted (see Fang $e t a l^{18}$ for more details on methods and links to the data set).

As with any research study, there are limitations that should be noted. Several countries in the region still have little to no data on child maltreatment and only a handful of countries have population-based prevalence studies. There is a variation in reported rates of maltreatment, which is a reflection of the differing measurement procedures and definitions across studies. Further research needs to be conducted on improving study designs and data collection in the region. ${ }^{19}$ The scope of this study required us to use a variety of different measures of burden across many studies and countries. The following burden estimates are conservative, given that we are unable to estimate the burden for a number of major categories of health and social outcomes. Even after conservative assumptions were made, and sensitivity analyses conducted, the estimated heavy social and economic burden of violence in the region underscores the need for a focus on prevention.

Figure 1 shows the prevalence estimates for each type of violence in the region. These prevalence estimates are from 14 child emotional violence studies, 40 child physical violence studies, 12 child neglect studies, 40 child sexual violence studies and 16 witnessing parental violence studies.

Emotional violence was reported by nearly one in three girls and one in four boys with similarly high

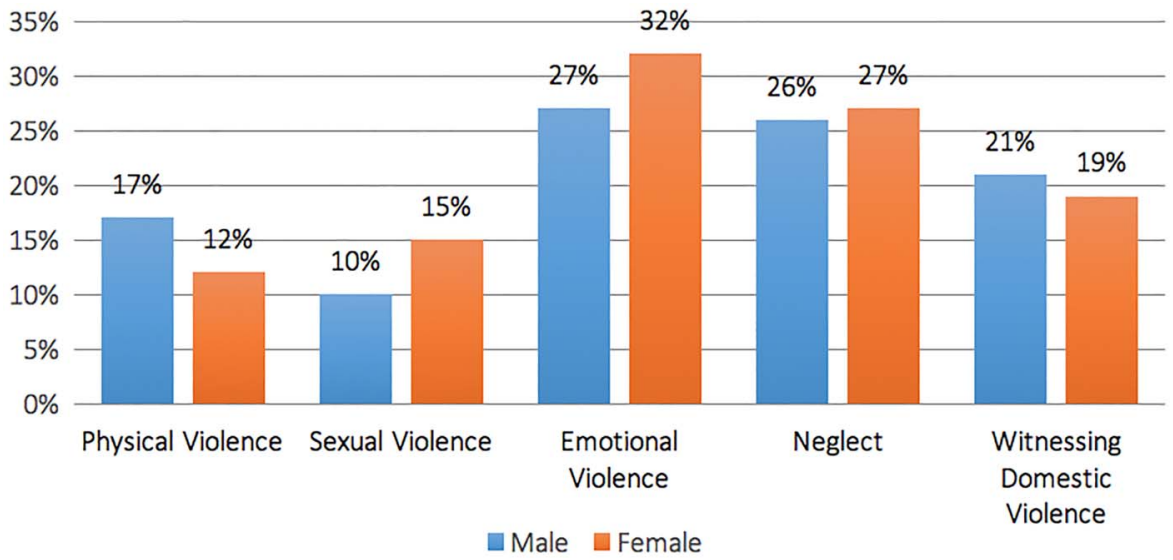

Figure 1 Prevalence of violence against children from 14 countries in the Asia and Pacific region, meta-analysis of 122 estimates, corrected for methodological factors and sample size weighted. Data from the following countries are included: Cambodia, China, Japan, Republic of Korea, Malaysia, Singapore, Philippines, Thailand, Viet Nam, Northern Mariana Islands, Palau, Marshall Islands, New Caledonia and Viet Nam. Separate meta-analyses were conducted for each type of violence and corrected for methodological variations that were significant at $15 \%$ level. (See Fang et al ${ }^{18}$ for more on calculations). Source: Calculation was performed specifically for this paper using raw data from the East Asia and Pacific Burden of Violence Study let by Fang and Fry. (See Fang et $a l^{18}$ for study information and meta-analyses by World Bank and WHO subregions). 
estimates found for neglect and witnessing domestic violence in the home (see figure 1). Recently completed Violence Against Children Surveys from Cambodia and Laos also point to the common occurrence of physical and emotional violence against children perpetrated by parents/caregivers, adults, peers and intimate partners. ${ }^{20}$ Where internationally comparable data exist, it shows that typically three of the four children experience violent discipline, ${ }^{21}$ and approval of corporal punishment is particularly pronounced in the Asia and Pacific region. ${ }^{22}$ Additional national studies on violence against children are nearing completion in the Philippines and Bhutan and are being planned in China.

Neglect is an under-researched area but one that has significant implications for children's social and cognitive development. The scarcity of data is due in part to problems associated with measuring it. In contrast to other forms of maltreatment, child neglect is committed by purposeful omission, making it difficult to observe in practice. ${ }^{6}$ In countries where national surveillance systems are in place, neglect is typically the most common form of abuse reported to child protection agencies. $^{23} 24$ However, in the region, surveys that include data on neglect have been conducted in only a handful of countries. Studies in China, for example, have shown that $67.1 \%$ of parents with a child aged 3-6 years emotionally neglected their children in the previous year ${ }^{25}$ and that $28 \%$ of parents with a child aged 3-6 years in 25 Chinese cities experienced neglect. ${ }^{26}$

Prevalence estimates show that 'sexual harassment' often appears a normal part of growing up for girls. For example, a regional review of violence against children in educational settings in South Asian countries found that sexual harassment was prevalent throughout the region and was perpetrated by educators and peers. ${ }^{27}$

New evidence has shed light on the extent to which boys are affected by sexual violence. For example, recently completed violence against children studies in Cambodia, Lao PDR and provisionally in Philippines show higher sexual violence prevalence against boys than girls. ${ }^{20} 2829$ The United Nations Multicountry study on Men and Violence in the Asia and Pacific region found that from $6 \%$ (Indonesia-rural) to $37 \%$ (Bangladesh-urban) of adult men reported experiencing sexual violence before the age of 18 including in the home. $^{30}$

School-based violence in the form of bullying is another common form of violence against children. Bullying is rarely a one-off incident, but an experience that many children endure on a routine basis throughout their school years. Data from the Global School Based Health Surveys from 25 countries in the region highlight a median bullying prevalence estimate of $33 \%$ -or approximately one in three students report experiencing bullying on at least one or more days in the past month in the region. The prevalence of 'cyberbullying' is less well known. However, as an act of violence can be performed at any time, from any location and be completely anonymous, it multiples risks many times beyond traditional school-based bullying. ${ }^{57}$

\section{Impact of violence against children on health and productivity}

Several studies have highlighted the burden of violence against children on health and well-being and conversely, how prevention could reduce health and health risk behaviours. In the USA, for example, data comparing Medicaid claim forms between patients found that those who had experienced violence during childhood had much larger short-term and long-term medical costs than those who had not experienced violence. ${ }^{31} 32$ Similarly, data on productivity losses in the USA found that losses per victim are in the range of over $\$ 1$ million (in 2010 US dollars). ${ }^{32}$ A recent study in Australia also found that child maltreatment contributes to a substantial proportion of the burden from depressive and anxiety disorders and intentional self-harm. ${ }^{33}$

Regional data highlight how all forms of violencephysical, sexual and emotional violence, neglect and witnessing domestic violence-bear a large burden on the proportion of negative health outcomes seen in the region. For example, figure 2 shows that around $25 \%$ of mental disorders, defined as Common Mental Disorders (such as depression, generalised anxiety disorder, post-traumatic stress disorder and obsessivecompulsive disorder), measured using the CIS-R (Revised Clinical Interview Schedule) in the Asia and Pacific region are linked to childhood experiences of emotional violence. $^{8}$

Figure 3 highlights how experiencing violence in childhood contributes to negative health outcomes and health risk behaviours, including illicit drug use, problem drinking, early smoking initiation, early sex and teenage pregnancy. Neuroscientific explanations correspond with this empirical evidence on the association of violence with negative health outcomes. For example, bodily response such as increased heart rate and shortness of breath are the result of the nervous system responses to high levels of stress for extended periods of time from experiencing or witnessing violence. This constant stress, over time, becomes detrimental to the body and will become normalised even when no stress is present. This results in a situation where individuals may respond to everyday situations with aggression or anger or see aggression in others where there is none. This creates adverse chronic stress that has negative health and well-being outcomes, including coping mechanisms throughout life. ${ }^{34} 35$

From regional data, preventing violence against children could reduce teenage pregnancy for girls, and sex before the age of 16 for boys and girls by a quarter $(25 \%)$. Likewise, investing in violence prevention could have a significant reduction on early smoking initiation (before the age of 15) for boys and girls by nearly $20 \%$ and reduce illicit drug use by adolescents 


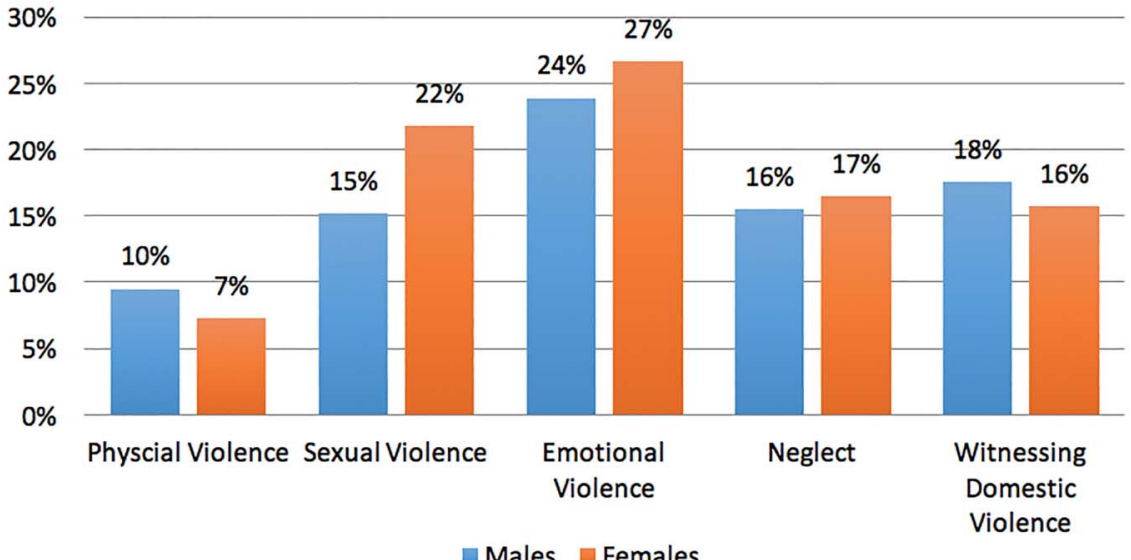

Figure 2 Proportion of mental disorders in the region attributable to having experienced violence during childhood, by type of violence experienced and gender. ${ }^{18}$ Calculations use PAFs, which are used to estimate the proportion of morbidity attributable to a risk factor. These calculations are based on 47 studies from the East Asia and Pacific Region which control for methodological variation and are sample-size-weighted. Source: Calculation was performed specifically for this paper using raw data from the East Asia and Pacific Regional Costing Study let by Fang and Fry. (See Fang et al ${ }^{18}$ for study information and PAFs for mental disorders by World Bank and WHO subregions). PAFs, population attributable fractions.

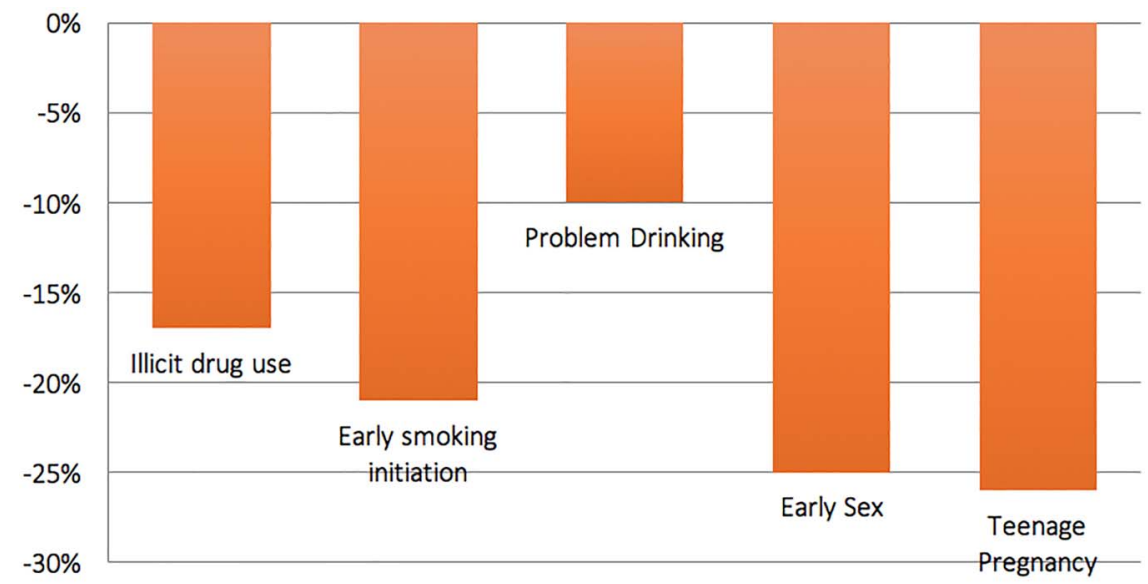

Figure 3 Preventing violence against children could reduce risk behaviours. ${ }^{18}$ Data include having experienced at least one form of physical violence, sexual violence, emotional violence, neglect or witnessing domestic violence. Problem drinking data available only for physical or sexual violence or witnessing domestic violence. Early sex data are available only for sexual violence and neglect, and teenage pregnancy data are available only for girls who have experienced sexual violence or witnessing domestic violence. These calculations are based on 47 studies from the East Asia and Pacific Region, which control for methodological variation and are sample-size-weighted. Source: Calculation was performed specifically for this paper using raw data from the East Asia and Pacific Regional Costing Study led by Fang and Fry. (See Fang et $a l^{18}$ for study information and PAFs by World Bank and WHO subregions). PAFs, population attributable fractions.

and adults by $17 \%$ and problem drinking for men and women by $10 \%$.

Violence against children also impacts on the productivity of a nation's population. Several costing studies have been conducted in the region to estimate the economic impact of violence against children and these are presented in table 1 . The study on the cost of domestic violence against women is also included as a reference only in table 1 .

A study on the regional burden of violence in East Asia and the Pacific that used a prevalence-based approach for estimating costs found that the total cost of violence against children, specifically on health and health risk behaviour outcomes costs $\$ 209$ billion (in 2013 US dollars) or nearly $2 \%$ of the region's gross domestic product (GDP). This includes costs for emotional violence $(\$ 65.9 \mathrm{bn})$, physical violence $(\$ 39.6 \mathrm{bn})$, sexual violence $(\$ 39.9 \mathrm{bn})$, neglect $(\$ 32.4 \mathrm{bn})$ and witnessing domestic violence $(\$ 31 \mathrm{bn}){ }^{18}$

\section{Impact of violence against children on educational outcomes}

The evidence base for the association of experience of violence with educational outcomes is still being 
Table 1 Cost of violence studies in the Asia and Pacific region

\begin{tabular}{|c|c|c|c|c|c|}
\hline Study & Countries included & Outcomes/costs included & Types of violence measured & $\begin{array}{l}\text { Total cost } \\
\text { of violence }\end{array}$ & $\begin{array}{l}\text { Cost of violence as } \\
\% \text { of GDP }\end{array}$ \\
\hline $\begin{array}{l}\text { Fang } \\
\text { et } a l^{18}\end{array}$ & $\begin{array}{l}\text { Indonesia, Thailand, Brunei, } \\
\text { Darussalam, Japan, Singapore, } \\
\text { Cambodia, China, Cook Islands, Fiji, } \\
\text { Kiribati, Lao PDR, Malaysia, Republic } \\
\text { of Marshall Islands, Micronesia, } \\
\text { Mongolia, Nauru, Niue, Palau, Papua } \\
\text { New Guinea, Philippines, Republic of } \\
\text { Korea, Samoa, Solomon Islands, } \\
\text { Tonga, Tuvalu, Vanuatu, Viet Nam }\end{array}$ & $\begin{array}{l}\text { Illicit drug use, early smoking initiation, } \\
\text { problem drinking, early sex, teenage } \\
\text { pregnancy, self-harm, stomach pain, } \\
\text { mental disorder }\end{array}$ & $\begin{array}{l}\text { Violence against children } \\
\text { including: emotional, physical } \\
\text { and sexual, neglect, witnessing } \\
\text { domestic violence, child } \\
\text { maltreatment deaths }\end{array}$ & $\begin{array}{l}\text { US } \$ 209 \\
\text { billion (2013) }\end{array}$ & $\begin{array}{l}2 \text { of the region's } \\
\text { GDP }\end{array}$ \\
\hline Fang $^{36}$ & Cambodia & $\begin{array}{l}\text { Health consequences (mental distress, } \\
\text { intimate partner violence perpetration, } \\
\text { self-harm, smoking, problem drinking, } \\
\text { sexually transmitted infections, moderate } \\
\text { injuries resulting from interpersonal } \\
\text { violence) and productivity losses (as } \\
\text { measured by educational attainment) }\end{array}$ & $\begin{array}{l}\text { Violence against children } \\
\text { including: physical, emotional } \\
\text { and sexual violence against } \\
\text { children }\end{array}$ & $\begin{array}{l}\text { US\$251.3 } \\
\text { million } \\
(2013)\end{array}$ & 1.65 of GDP \\
\hline $\begin{array}{l}\text { Fang } \\
\text { et } a \beta^{\beta 7}\end{array}$ & China & $\begin{array}{l}\text { Mental disorder (depression and anxiety), } \\
\text { current smoker, problem drinking, illicit } \\
\text { drug use, self-harm }\end{array}$ & $\begin{array}{l}\text { Violence against children } \\
\text { including: emotional, physical } \\
\text { and sexual violence }\end{array}$ & $\begin{array}{l}\text { US } \$ 101 \\
\text { billion }\end{array}$ & 1.7 \\
\hline $\begin{array}{l}\text { Pollett and } \\
\text { Gurr }\end{array}$ & Vanuatu & $\begin{array}{l}\text { Direct costs (hospitalisation-emergency } \\
\text { care, non-hospital emergency care, mental } \\
\text { health treatment, child welfare service, law } \\
\text { enforcement), indirect costs (special } \\
\text { education, juvenile criminality, adult } \\
\text { criminality cost), life-long costs (chronic } \\
\text { health cost, lost productivity) }\end{array}$ & $\begin{array}{l}\text { Violence against children } \\
\text { including: emotional, physical } \\
\text { and sexual violence and neglect }\end{array}$ & $\begin{array}{l}\text { Vt } 293.8 \\
\text { million-Vt } \\
425.4 \text { million }\end{array}$ & $\begin{array}{l}0.5-0.75 \text { of GDP for } \\
\text { annualised costs } \\
\text { (direct, indirect and } \\
\text { lifelong) } \\
6.8 \text { of annual GDP } \\
\text { for life-long costs }\end{array}$ \\
\hline $\begin{array}{l}\text { UN } \\
\text { Women } \\
\text { Viet } \\
\text { Nam }^{39}\end{array}$ & Viet Nam & $\begin{array}{l}\text { Household-level direct and indirect costs } \\
\text { (out-of-pocket expenditures to utilise } \\
\text { services such as medical, treatment, police } \\
\text { and legal support, etc, income loss due to } \\
\text { missed work, loss of productivity for the } \\
\text { household, missed schooling by children); } \\
\text { cost of service provision and prevention } \\
\text { services (salaries, training costs, } \\
\text { operational costs such as rent, electricity, } \\
\text { etc) }\end{array}$ & $\begin{array}{l}\text { Domestic violence against } \\
\text { women }\end{array}$ & $\begin{array}{l}\text { VND } 2.5 \\
\text { billion }\end{array}$ & $\begin{array}{l}1.4 \text { of } 2010 \text { GDP } \\
\text { (total direct/indirect } \\
\text { costs of domestic } \\
\text { violence) } \\
1.78 \text { of GDP for total } \\
\text { productivity losses }\end{array}$ \\
\hline
\end{tabular}


established, but globally links have been made, suggesting greater recourse to special education, higher rates of grade repetition and lower grades among children who have been maltreated. ${ }^{40}$

For the first time, longitudinal data from the region have also shown that violence impacts on children's 'foundation skills' of reading, maths and vocabulary. Data from the Young Lives study have shown that children in two states in India and Viet Nam who reported experiencing corporal punishment in schools at age 8 have poorer cognitive outcomes and math scores, and lower self-esteem and self-efficacy than their non-abused peers. ${ }^{41}$ Children who reported corporal punishment at age 8 also performed significantly less well in maths tests at age 12 in India and Viet Nam and the effects on vocabulary scores were also significantly lower for children in India. ${ }^{41}$

\section{Impact of violence against children on intergenerational violence, adult criminality and juvenile offending}

Strong links have been made in the evidence throughout the region between violence during childhood and later violence in adulthood, particularly for intimate partner violence. Figure 4 shows the forms of violence and crime that could be reduced in the region if sexual violence during childhood was prevented. The focus on sexual violence is due to the existence of strong studies exploring the associations between this particular form of violence during childhood and other forms of violence in adolescence and adulthood.

Data show that nearly a third of lifetime intimate partner violence victimisation for women could be averted if sexual violence during childhood was prevented. Data also show that carrying a weapon and injuring or threatening someone with a weapon could be reduced by approximately a quarter $(21-27 \%$, respectively) for women and by $15-20 \%$ for men in the region.

\section{Hurdles to progress}

These data show that investments for the prevention of violence in childhood can bring economic returns by reducing negative health outcomes and productivity losses, reducing public expenditure for tertiary responses to reported incidents, increasing children's developmental and educational outcomes and decreasing intergenerational violence, adult criminality and juvenile offending. While the identification of causeeffect relationships for violence is problematic, the notion of 'drivers' is being employed in the region to refer to factors at the institutional and structural levels that create the conditions in which violence is more likely to occur. ${ }^{42}$

Our understanding of determinants that are common in the Asia and Pacific region is improving. While it is difficult, if not impossible, to generalise given the great diversity and complexity of societies and cultures (eg, there are over 300 ethnic groups residing in Indonesia alone), there are common risk factors presented in studies from the region, which provide hurdles to progress towards prevention. ${ }^{42-44}$ In many countries, the relatively low status of children in societies and families means children are perceived as 'belonging or indebted to' their parents and caretakers. ${ }^{43}{ }^{44}$ Violence is often not publicly discussed or reported, and thus often remains invisible and normalised. ${ }^{45}$ This in addition to other community and societal risk factors identified in the literature such as a tolerance of violence, substance abuse, gender and social inequalities, lack of services to support families, high levels of unemployment, poverty and inadequate policies and programmes within institutions make the occurrence of violence against children more likely. ${ }^{17} 42-44$

Studies identified that particular groups of children are at higher risk of experiencing violence in the region. This includes children with disabilities, ${ }^{46}{ }^{47}$ married girls, ${ }^{48}$ children in conflict with the law ${ }^{7}$ and children in out-of-home care. $^{49}$

While great advances have been achieved in the region in addressing risk factors by, for example, strengthening the rule of law, reducing infant mortality, improving access to education and reducing poverty, new trends have emerged that are increasing risk for children. These include the growth of information and communications technologies which generate new forms of child abuse and exploitation; ${ }^{50}{ }^{51}$ the pace and scale of urban migration in the region that hosts half of the world's megacities, which places children at risk by decreasing family support networks, increasing family stress and increasing the numbers of children 'leftbehind' in precarious care situations by migrating parents; ${ }^{52} 53$ and the impacts of armed conflict and ensuing grave violations of children's rights in countries such as Afghanistan, Myanmar and Philippines. ${ }^{54}$

\section{Ways forward for government and development partners}

This paper has highlighted how frequently occurring forms of violence against children have well documented long-term impacts on brain development, and on the creation of cognitive and human capital. Investment in preventing violence against children is pivotal. The following represent some of the high-impact evidencebased actions that government and development partners can implement to leverage change in order to enhance children's educational and health outcomes and to build healthier economies in the Asia and Pacific region.

Governments need to tighten their legislation to ensure the comprehensive prohibition of all forms of violence against children. From a child rights perspective, any form of violence, however light, is unacceptable. Frequency, severity of harm and intent to harm are not prerequisites for definitions of violence. ${ }^{2}$ Even mild forms of physical and verbal violence committed in the guise of 'discipline' by parents or teachers can have detrimental developmental and educational impacts. This year, Mongolia has joined 48 other states around 


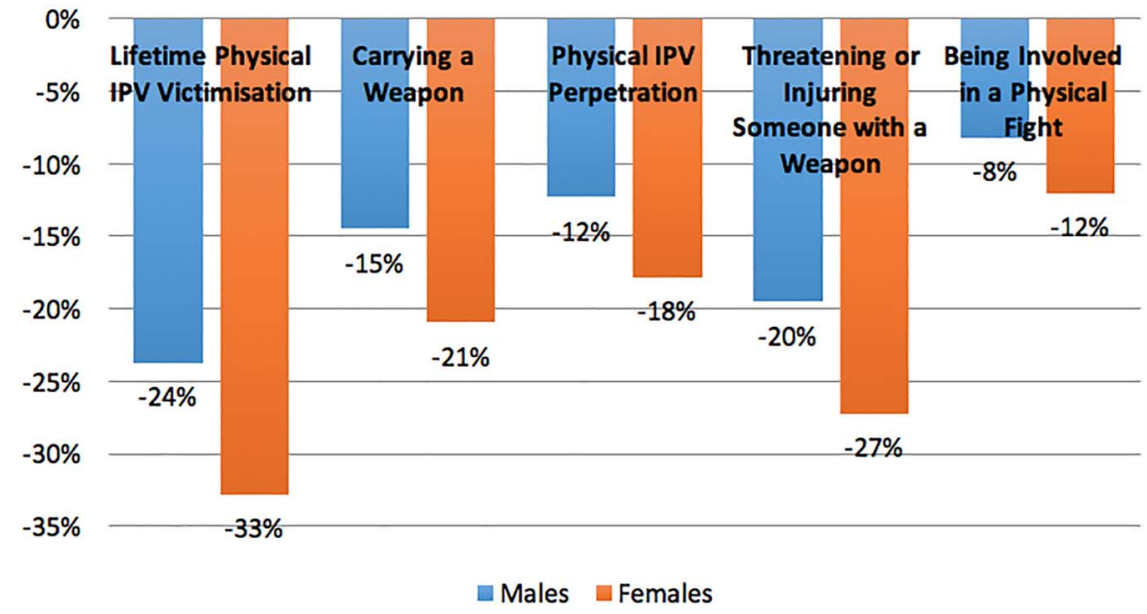

Figure 4 Preventing sexual violence during childhood can reduce other forms of violence, population attributable fractions by gender. ${ }^{18}$ Physical IPV perpetration, threatening or injuring someone with a weapon and being involved in a fight measure past year prevalence, carrying a weapon is past month prevalence. All PAFs control for significant methodological variations and are sample size weighted. Source: Calculation using raw data from the East Asia and Pacific Regional Costing Study led by Fang and Fry. (See Fang et al ${ }^{18}$ for study information and PAFs by World Bank and WHO subregions). PAFs, population attributable fractions.

the world in prohibiting corporal punishment in all settings-including the home-and is the first in the Asia and Pacific region.

Laws alone are not enough to prevent violence; the enforcement of laws is also a crucial part of this strategy for prevention. Developing and strengthening legal protections and policies for children must be combined with the means to enforce these protections in order to prevent violence against children. For example, the WHO Global Status Report on Violence Prevention found that while laws relating to bans on corporal punishment were reported to exist in $76 \%$ of countries globally, only $30 \%$ of these countries indicated the enforcement of such laws. ${ }^{55}$ Behaviours may also be underpinned by social norms, or the beliefs and expectations about what others do and what others think we should do that are maintained by the social approval and disapproval. If a harmful practice is social in nature, programmes that only concentrate on the education of the individual or the enforcement of a specific behaviour may not be enough to change the social practice. ${ }^{56}$ Programmes may be more effective if they support the revision of social expectations or the promotion of positive social norms throughout the community. ${ }^{56}$

Governments thus have a key role to play in creating an environment of open public dialogue on difficult and sensitive child protection issues. Communications initiatives are needed to challenge the social acceptance of violence against children. These must be accompanied by coordinated public education efforts for parents and caregivers on positive, non-violent parenting; and for children on specific risks and self-protection.

A global partnership to end violence against children was launched in July 2016, with an overall aim to support efforts to achieve SDG Target 16.2: the end of abuse, exploitation, trafficking, torture and all forms of violence against children by 2030. It is an inclusive platform that draws membership from governments, UN Agencies, civil society, the private sector, philanthropic organisations, academia and others (see WHO et al, ${ }^{17}$ for more information about the Global Partnership). As part of this partnership, major agencies such as the Centers for Disease Control (CDC), the President's Emergency Plan for AIDS Relief (PEPFAR), Together for Girls, United Nations Children's Fund (Unicef), the USA Agency for International Development (USAID), the WHO and the World Bank have come together to assemble the best available evidence on interventions that have shown success in reducing violence against children. Through this effort, 'seven strategies' have been identified to help countries and communities intensify their focus on violence prevention:

1. implement and enforce laws to protect children,

2. value social norms and values that protect children,

3. sustain safe environments for children,

4. provide parent and caregiver support,

5. empower families economically,

6. raise access to response and support services,

7. help children develop life skills and stay in school. ${ }^{17}$

These seven strategies should be complimented by robust monitoring and evaluation and multisectorial coordination. Governments and development partners plans for preventing violence against children should be informed by the 'seven strategies' when designing comprehensive national agendas that include a national coordinating framework, sufficient human and technical resources, and robust mechanisms for monitoring and accountability. Importantly and given the "whole-ofgovernment' approach for these efforts, high-level 
interministerial oversight of this agenda will need to be established.

Assessment of progress in preventing and reduction in violence against children has long been hampered by gaps in measurement throughout the region. Data collection on children's experience of violence carries with it a myriad of methodological and ethical challenges. Nevertheless, the availability of comparable data on certain forms of violence has improved, and the possibility of including key indicators in regular household survey programmes has been demonstrated. For example, SDG target 16.2 requires the measurement of violent discipline and sexual violence. In the region, 10 of the 32 countries include the measurement of violent discipline in current international survey programmes (such as Demographic and Health Surveys or Multi-Indicator Cluster Surveys). Of the 43 countries globally that collect data on sexual violence through such programmes, only 5 are in the Asia and Pacific region and do not currently collect data on boys.

A dedicated research programme will also be necessary to deepen understanding of the incidence, prevalence, circumstances and risk factors for violence against children. Such a programme could comprise three components. First, a population-based national violence against children survey, such as those being planned or implemented in Bhutan, Cambodia, China, Indonesia, Lao PDR and the Philippines; second, the development of surveillance systems based on administrative data on actual incidences of reported violence from mandated Agencies; and third, qualitative and quantitative studies on the contextual drivers of violence, to inform effective targeting of prevention initiatives.

\section{CONCLUSION}

Violence is a common experience in the lives of children in the Asia-Pacific region, and impacts on their health and well-being as they grow through adolescence into adulthood. This paper details, for the first time, an investment case for prevention of violence against children in the Asia-Pacific region using regional data. 'Cognitive capital' - the outcome of investing in healthy brain development of children-has the potential to drive the region's economies now and into the future. The cumulative effects of violence experienced in childhood have measurable social and economic impacts that significantly undermine these efforts to build this 'cognitive capital'. The global movement to end violence against children has received greater prominence due to the inclusion of key targets in the SDGs. Governments in the region must recognise that these efforts should figure prominently within their national development agendas. While ending violence against children remains a moral and legal imperative, the adoption of existing evidence-based strategies is a wise and essential investment for governments in the Asia and Pacific region.
Handling editor Seye Abimbola

Contributors DF and SB researched, wrote and edited the manuscript.

Funding This work was funded from the resources of Unicef.

Disclaimer This paper is based on a longer thematic report presented on November 7th and 8th, 2016 at the UNICEF High Level Meeting on SouthSouth Cooperation for Child Rights in Asia and the Pacific. The opinions expressed in this paper are solely those of the authors and do not necessarily represent the views or policies of UNICEF or any other agency.

Competing interests None declared.

Provenance and peer review Not commissioned; externally peer reviewed.

Data sharing statement No additional data are available.

Open Access This is an Open Access article distributed in accordance with the Creative Commons Attribution Non Commercial Non Derivative (CC BYNC-ND 4.0) license, which permits users to copy, distribute and transmit an article as long as the author is attributed, the article is not used for commercial purposes, and the work is not modified or adapted in any way. See: http://creativecommons.org/licenses/by-nc-nd/4.0/legalcode

\section{REFERENCES}

1. United Nations General Assembly. Convention on the rights of the child, Geneva: United Nations, 1989.

2. United Nations. General comment No. 13 (2011): the right of the child to freedom from all forms of violence. New York: United Nations Committee on the Rights of the Child, 2011.

3. Pinheiro PS. UN secretary general's world report on violence against children. Geneva: United Nations, 2006.

4. United Nations Children's Fund (UNICEF). Measuring and monitoring child protection systems: proposed core indicators for the East Asia and Pacific region, strengthening child protection series No. 1. Bangkok: UNICEF EAPRO, 2012.

5. Hillis SD, Mercy JA, Amobi A, et al. Global prevalence of past-year violence against children: a systematic review and minimum estimates. Pediatrics 2016;137:e20154079.

6. United Nations Children's Fund (UNICEF). Hidden in plain sight: a statistical analysis of violence against children. New York: UNICEF, 2014.

7. United Nations Children's Fund (UNICEF). Legal protection from violence: analysis of domestic laws related to violence against children in ASEAN member states. Bangkok: UNICEF EAPRO, 2015.

8. Fry DA, McCoy A, Swales D. The consequences of maltreatment on children's lives: a systematic review of data from the East Asia and Pacific region. Trauma Violence Abuse 2012;13:209-33.

9. Coates D. Impact of childhood abuse: biopsychosocial pathways through which adult mental health is compromised. Australian Social Work 2010;63:391-403.

10. Shonkoff JP, Garner AS. The lifelong effects of early childhood adversity and toxic stress. Pediatrics 2012;129:e232-46.

11. Tomoda A, Sheu YS, Rabi K, et al. Exposure to parental verbal abuse is associated with increased gray matter volume in superior temporal gyrus. Neuroimage 2011;54(Suppl 1):S280-6.

12. Tomoda A, Navalta CP, Polcari A, et al. Childhood sexual abuse is associated with reduced gray matter volume in visual cortex of young women. Biol Psychiatry 2009;66:642-8.

13. Huang G, Zhang Y, Zou S, et al. Plasma Neuropeptide-Y and cognitive function in female inmates with childhood sexual abuse. Chin J Psychiatry 2006;39:12-5.

14. Allard C. Prevalence and sequelae of betrayal trauma in a Japanese student sample. Psychol Trauma 2009;1:65-77.

15. Tomoda A, Suzuki H, Rabi K, et al. Reduced prefrontal cortical gray matter volume in young adults exposed to harsh corporal punishment. Neuroimage 2009;47(Suppl 2):T66-71.

16. Sheu YS, Polcari A, Anderson CM, et al. Harsh corporal punishment is associated with increased T2 relaxation time in dopamine-rich regions. Neuroimage 2010;53:412-19.

17. World Health Organization (WHO), Centers for Disease Control and Prevention (CDC), Global Partnership to End Violence Against Children, et al. INSPIRE: seven strategies for ending violence against children. Geneva: WHO, 2010.

18. Fang X, Fry DA, Brown DS, et al. The burden of child maltreatment in the East Asia and Pacific region. Child Abuse Negl 2015;42:146-62. 
19. United Nations Children's Fund (UNICEF). Violence against children in East Asia and the Pacific: a regional review and synthesis of findings, strengthening child protection series No. 4. Bangkok: UNICEF EAPRO, 2014.

20. Ministry of Women's Affairs, UNICEF Cambodia, US Centers for Disease Control and Prevention (CDC). Findings from Cambodia's violence against children survey 2013. Phnom Penh: Ministry of Women's Affairs, 2014.

21. United Nations Children's Fund (UNICEF). UNICEF global database: violent discipline. New York: UNICEF, 2016.

22. Straus M. International dating violence study, 2001-2006. In: Strauss MA, Douglas EM, Medieros RA. The primordial violence: spanking children, psychological development, violence and crime. New York: Routledge, 2014:47-9.

23. Australian Institute of Health and Welfare (AIHW). Child protection Australia 2013-14, Child welfare series no. 61, Cat. no. CWS 52. Canberra: AlHW, 2015.

24. Public Health Agency of Canada. Canadian incidence study of reported child abuse and neglect-2008: major findings. Ottawa: Public Health Agency of Canada, 2010.

25. Cui LH, Pang SL, Du WR, et al. Prevalence of physical and emotional maltreatment by parents in preschool children. Chin J Public Health 2010;26:486-7.

26. Pang JP, Yang ZN, Ren $\mathrm{XH}$, et al. [Study on the current situation and influential factors of child neglect among aged 3-6 year-olds in the urban areas of China]. Zhonghua Liu Xing Bing Xue Za Zhi 2005;26:258-62.

27. United Nations Children's Fund Regional Office for South Asia (UNICEF ROSA). Violence against children in education settings in South Asia: a desk review. Kathmandu: UNICEF ROSA, 2016.

28. Lao Statistics Bureau, National Commission for Mothers and Children (NCMC), and United Nations Children's Fund (UNICEF). Violence against children survey in Lao PDR: Preliminary report. Vientiane Capital: Lao Statistics Bureau, NCMC and UNICEF, 2016.

29. United Nations Children's Fund (UNICEF) Philippines, the Department of Health (DOH), the Philippine Council for Health and Research and Development (PCHRD), et al. Violence against children: preliminary results of the national baseline study on violence against children in the Philippines. http://www.unicef.org/ philippines/VACFactsheet.pdf (accessed Aug 2016).

30. Fulu E, Warner X, Miedema S, et al. Why do some men use violence against women and how can we prevent it? Quantitative findings from the United Nations multi-country study on men and violence in Asia and the Pacific. Bangkok: United Nations Development Programme, United Nations Population Fund, United Nations Women and United Nations Volunteers, 2014.

31. Florence C, Brown DS, Fang X, et al. Health care costs associated with child maltreatment: impact on Medicaid. Pediatrics 2013;132:312-18.

32. Fang X, Brown DS, Florence CS, et al. The economic burden of child maltreatment in the United States and implications for prevention. Child Abuse Negl 2012;36:156-65.

33. Moore SE, Scott JG, Ferrari AJ, et al. Burden attributable to child maltreatment in Australia. Child Abuse Negl 2015;48:208-20.

34. Patel DM, Taylor RM. Social and economic costs of violence Workshop summary. Forum on Global Violence Prevention. Washington, DC: National Academy of Sciences, 2011.

35. Teicher MH, Samson JA. Annual research review: enduring neurobiological effects of childhood abuse and neglect. J Child Psychol Psychiatry 2016;57(3):241-66.

36. Fang $\mathrm{X}$. The economic burden of health consequences of violence against children in Cambodia. Phnom Penh: UNICEF Cambodia, 2015.

37. Fang X, Fry DA, Ji K, et al. The burden of child maltreatment in China: a systematic review. Bull World Health Organ, 2015;93:176-85C.
38. Pollett J, Gurr S. Lifting the financial burden of child abuse: a Vanuatu case study. Suva, Fiji: UNICEF Pacific, 2009.

39. UN Women Viet Nam. Estimating the costs of domestic violence against women in Viet Nam. Hanoi: United Nations, 2012.

40. Romano E, Babchishin L, Marquis R, et al. Childhood maltreatment and educational outcomes. Trauma Violence Abuse 2015;16:418-37.

41. Portela MJO, Pells K. Corporal punishment in schools: longitudinal evidence from Ethiopia, India, Peru and Viet Nam, Innocenti discussion papers. Florence: UNICEF Office of ResearchInnocenti, 2015

42. Maternowska MC, Potts A, Fry D. The multi-country study on the drivers of violence affecting children: synthesis of key findings. Florence: UNICEF Office of Research-Innocenti. In press.

43. Solotarff JL, Pande RP. Violence against women and girls: lessons from South Asia. Washington, DC: World Bank, 2014.

44. University of the Philippines Manila, The University of Edinburgh, Child Protection Network Foundation, et al. A systematic review of the drivers of violence affecting children in the Philippines. Manila: UNICEF Philippines, 2016.

45. World Health Organization (WHO). Violence prevention the evidence: series of briefings on violence prevention. Geneva: WHO, 2010.

46. Chan KL, Emery CR, Ip P. Children with disability are more at risk of violence victimization: evidence from a study of school-aged Chinese children. J Interpers Violence 2016;31:1026-46.

47. Jones L, Bellis MA, Wood S, et al. Prevalence and risk of violence against children with disabilities: a systematic review and meta-analysis of observational studies. Lancet 2012;380:899-907.

48. International Institute for Population Sciences (IIPS), Macro International. National family health survey (NFHS-3), 2005-06: India: volume I. Mumbai: IIPS, 2007.

49. Nelson CA III, Fox NA, Zeanah CH Jr. Anguish of the abandoned child: the plight of orphaned Romanian children reveals the psychic and physical scars from first years spent without a loving, responsive caregiver. Sci Am 2013;308:62-7.

50. Safaria T. Prevalence and impact of cyberbullying in a sample of Indonesian junior high school students. TOJET 2016;15:82-91.

51. United Nations Children's Fund (UNICEF). Child protection in the digital age: national responses to online child sexual abuse and exploitation in ASEAN member states. Bangkok: UNICEF EAPRO, 2016.

52. United Nations Economic and Social Commission for Asia and the Pacific (UNESCAP), United Nations Human Settlements Programme (UN-Habitat). The state of Asian and Pacific cities 2015: urban transformations shifting from quantity to quality. Bangkok: UNESCAP, UN-Habitat, 2015.

53. National Bureau of Statistics in China, United Nations Population Fund (UNFPA), United Nations Children's Fund (UNICEF). What census data can tell us about children in China: facts and figures. Beijing: National Bureau of Statistics in China, UNFPA and UNICEF, 2013.

54. United Nations Secretary General. Report on children and armed conflict, A/69/926-S/2015/409. New York: General Assembly Security Council, 2015.

55. World Health Organization (WHO). WHO global status report on violence prevention 2014. Geneva: WHO, 2014.

56. Mackie G, Moneti $\mathrm{F}$, Shakya $\mathrm{H}$, et al. What are social norms? How are they measured? UNICEF \& University of California, San Diego Center on Global Justice, 2015. http://www.unicef.org/protection/files/ 4_09_30_Whole_What_are_Social_Norms.pdf (accessed 11 Oct 2016).

57. Goebert D, Else I, Matsu C, et al. The impact of cyberbullying on substance use and mental health in a multiethnic sample. Matern Child Health J 2011;15:1282-6. 